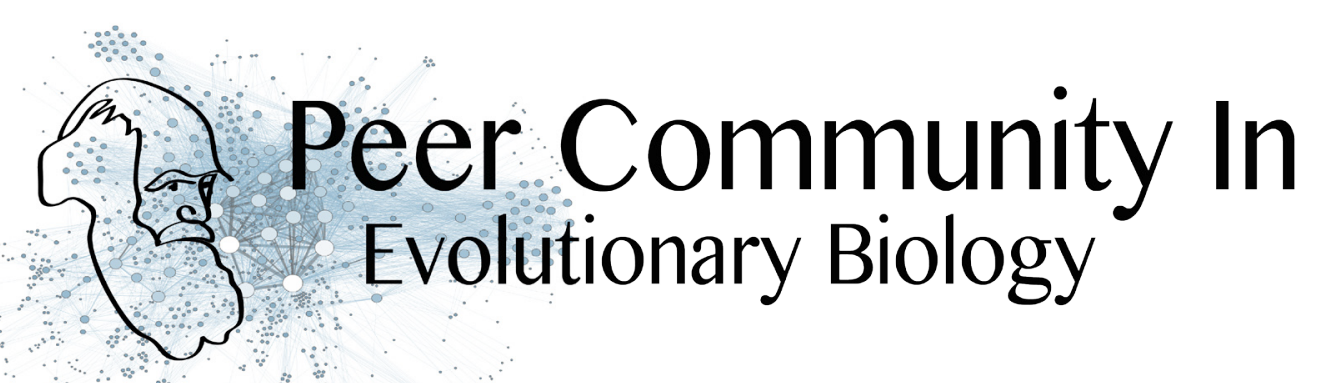

\title{
Dating nodes in a phylogeny using inferred horizontal gene transfers
}

\author{
Tatiana Giraud ${ }^{1}$ and Toni Gabaldón ${ }^{2}$
}

1 Laboratoire Ecologie, Systématique et Evolution, Univ. Paris Sud, CNRS, Université ParisSaclay - 91400 Orsay, France

2 Centre for Genomic Regulation (CRG), Barcelona Institute of Science and Technology --

Barcelona, Spain

Correspondence to Tatiana Giraud (tatiana.giraud@u-psud.fr)

doi: $10.24072 /$ pci.evolbiol.100037

\section{Open Access}

Cite as: Giraud T. and Gabaldón T. 2017. Dating nodes in a phylogeny using inferred horizontal gene transfers. Peer Community in Evolutionary Biology, 100037. doi: 10.24072/pci.evolbiol.100037

Published: 7 th November 2017

Copyright: This work is licensed under the Creative Commons

Attribution-NoDerivatives 4.0 International License. To view a copy of this license, visit

http://creativecommons.org/licen ses/by-nd/4.0/

\begin{abstract}
A recommendation - based on reviews by Mukul Bansal, Alexandros Stamatakis and an anonymous reviewer - of

Chauve C, Rafiey A, Davin AA, Scornavacca C, Veber P, Boussau B, Szöllösi GJ, Daubin V, Tannier E. 2017. MaxTiC: Fast ranking of a phylogenetic tree by Maximum Time Consistency with lateral gene transfers. bioRxiv, 127548, ver. 6 of $6^{\text {th }}$ November 2017. doi: $10.1101 / 127548$
\end{abstract}

Dating nodes in a phylogeny is an important problem in evolution and is typically performed by using molecular clocks and fossil age estimates [1]. The manuscript by Chauve et al. [2] reports a novel method, which uses lateral gene transfers to help ordering nodes in a species tree. The idea is that a lateral gene transfer can only occur between two species living at the same time, which indirectly informs on node relative ages in a phylogeny: the donor species cannot be more recent than the recipient species. Horizontal gene transfers are increasingly recognized as frequent, even in eukaryotes, and especially in microorganisms that have little fossil records [3-7]. Yet, such an important source of information has been very rarely used so far for inferring relative node ages in phylogenies. In this context, the method by Chauve et al. [2] represents an innovative and original approach to a difficult problem. An obvious limitation of the approach is that it relies on inferences of horizontal transfers, which detection is in itself a difficult problem. Incomplete taxon sampling, or the extinction of the true donor lineage may render patterns difficult to interpret in a temporary fashion. Yet, for clades with no fossils this may be the only piece of information 
we have at hand, and the growing amount of sequence data is likely to minimize issues derived from incomplete sampling.

The developed method, MaxTiC (for Maximal Time Consistency) [2], represents a very nice application of theoretical developments on the well-known «Feedback Arc Set» computer science problem to the evolutionary question of ordering nodes in a phylogeny. MaxTiC uses as input a species tree and a set of time constraints based on lateral gene transfers inferred using other softwares, and minimizes conflicts between node ordering and these time constraints. The application of MaxTiC on simulated datasets indicated that node ordering was fairly accurate [2]. MaxTiC is implemented in a freely available software, which represents original and relevant contribution to the field of evolutionary biology.

\section{References}

[1] Donoghue P and Smith M, editors. 2003. Telling the evolutionary time. CRC press.

[2] Chauve C, Rafiey A, Davin AA, Scornavacca C, Veber P, Boussau B, Szöllősi GJ, Daubin V and Tannier E. 2017. MaxTiC: Fast ranking of a phylogenetic tree by Maximum Time Consistency with lateral gene transfers. bioRxiv 127548, ver. 6 of $6^{\text {th }}$ November 2017. doi: 10.1101/127548

[3] Ropars J, Rodríguez de la Vega RC, Lopez-Villavicencio M, Gouzy J, Sallet E, Debuchy R, Dupont J, Branca A and Giraud T. 2015. Adaptive horizontal gene transfers between multiple cheese-associated fungi. Current Biology 19, 25622569. doi: 10.1016/j.cub.2015.08.025

[4] Novo M, Bigey F, Beyne E, Galeote V, Gavory F, Mallet S, Cambon B, Legras JL, Wincker P, Casaregola S and Dequin S. 2009. Eukaryote-to-eukaryote gene transfer events revealed by the genome sequence of the wine yeast Saccharomyces cerevisiae EC1118. Proceeding of the National Academy of Science USA, 106, 16333-16338. doi: 10.1073 /pnas.0904673106

[5] Naranjo-Ortíz MA, Brock M, Brunke S, Hube B, Marcet-Houben M, Gabaldón T. 2016. Widespread inter- and intradomain horizontal gene transfer of d-amino acid metabolism enzymes in Eukaryotes. Frontiers in Microbiology 7, 2001. doi: 10.3389/fmicb.2016.02001

[6] Alexander WG, Wisecaver JH, Rokas A, Hittinger CT. 2016. Horizontally acquired genes in early-diverging pathogenic fungi enable the use of host nucleosides and nucleotides. Proceeding of the National Academy of Science USA. 113, 4116-4121. doi: 10.1073/pnas.1517242113

[7] Marcet-Houben M, Gabaldón T. 2010. Acquisition of prokaryotic genes by fungal genomes. Trends in Genetics. 26, 5-8. doi: 10.1016/j.tig.2009.11.007

\section{Appendix}

Reviews by Mukul Bansal, Alexandros Stamatakis and an anonymous referee: http://dx.doi.org/10.24072/pci.evolbiol.100037 